\title{
Microscopia eletrônica de varredura de duas espécies de Fannia Robineau-Desvoidy (Diptera, Fanniidae)
}

\author{
Ariel David Freitas Al Gazi ${ }^{1,3}$, Muracy Bélo ${ }^{1}$ Jaime Maia dos Santos ${ }^{2}$
}

\begin{abstract}
${ }^{1}$ Departamento de Biologia Aplicada à Agropecuária, Faculdade de Ciências Agrárias e Veterinárias, Universidade Estadual Paulista. Via de Acesso Professor Paulo Donato Castelane s/n. 14.884-900 Jaboticabal-SP, Brasil.

Endereço eletrônico: arifranca@yahoo.com.br; mbelo@fcav.unesp.br

${ }^{2}$ Departamento de Entomologia Agrícola, Faculdade de Ciências Agrárias e Veterinárias, Universidade Estadual Paulista. Via de Acesso Professor Paulo Donato Castelane s/n. 14.884-900 Jaboticabal-SP, Brasil. Endereço eletrônico: jmsantos@fcav.unesp.br

${ }^{3}$ Bolsista do CNPq.
\end{abstract}

\begin{abstract}
Scanning electron microscopy in two species of Fannia Robineau-Desvoidy, (Diptera, Fanniidae). The species Fannia pusio Wiedemann, 1830 and F. trimaculata Stein, 1898 belong to the canicularis group and pusio subgroup. These species are morphologically very similar and usually distinguished from each other by a line of bristles on the males hind femur. The scanning electron microscopy analysis showed a smaller number of orifices on the dorsal surface of the egg in the structure called "cellas" and, on the ventral surface, less rugosity was noted, both in F. trimaculata. On the larvae, the stigma or protothoracic spiracle was outstanding, where F. trimaculata possess two short tegumental extensions and seven long ones, while $F$. pusio has nine extensions, all long, of equal length. Males of $F$. trimaculata present alongside a line of longer bristles located more externally on the facet, another line of shorter bristles, which is absent in males of $F$. pusio, but present in females of both species.
\end{abstract}

KEYwords. Differences; Fannia pusio; Fannia trimaculata; morphology; SEM.

\begin{abstract}
Resumo. As espécies Fannia pusio Wiedeman, 1830 e Fannia trimaculata Stein, 1898 pertencem ao grupo canicularis e ao subgrupo pusio. Estas espécies são morfologicamente muito similares e geralmente são diferenciadas por uma fileira de cerdas no fêmur do terceiro par de pernas do macho. A análise com microscopia eletrônica de varredura mostrou na estrutura denominada "cellas", menor número de orifícios na superfície dorsal do ovo e, na superfície ventral, foi detectado menor rugosidade, ambos em F. trimaculata. Na larva, o estigma ou espiráculo protorácico é proeminente, onde $F$. trimaculata apresentou duas expansões tegumentares pequenas e sete longas de igual comprimento. Os machos de F. trimaculata apresentam uma fileira de cerdas localizadas mais externamente na faceta e, outra fileira de cerdas menores, a qual é ausente em machos de F. pusio, porém presente nas fêmeas de ambas as espécies.
\end{abstract}

Palavras-chave. Fannia pusio; Fannia trimaculata; morfologia; SEM.

A família Fanniidae é constituída por espécies que guardam muita semelhança entre si (SEAGo 1954; ChillCotT 1960, 1961; AlbuQUERQue et al. 1981). O tegumento é geralmente escuro, ainda que coberto por pilosidade clara. Segundo GUIMARÃEs et al. (1983), estas moscas apresentam tamanho médio a pequeno, olhos grandes, genas estreitas e probóscide curta. Os principais caracteres utilizados na identificação de moscas do gênero Fannia, são a quarta veia longitudinal $\mathrm{M}_{1+2}$ não se curvando para encontrar a $\mathrm{R}_{4+5}$ e a segunda veia Anal curvando-se em direção à primeira (AxTELL 1986).

As espécies de Fannia desenvolvem-se em quase todos os tipos de matéria orgânica em decomposição (WESt 1951; Guimarães 1984; QueIroz \& CARVALHo 1987). No Brasil, estas moscas são habitantes comuns de granjas de galinhas poedeiras; a presença nestes ambientes foi assinalada por Aagesen (1988), Prado \& Ribeiro (1989), Ribeiro \& Prado (1989), BÉLo (1991), BRUNo et al. (1993), em vários municípios do Estado de São Paulo e por Lomônaco \& Prado (1994) em Uberlândia, Estado de Minas Gerais. A freqüência de ocorrência nesses locais varia de 5 a 15\% (PRADo \& RibeIRo 1989; Bruno et al. 1993; Lomônaco \& Prado 1994; Bélo et al. 1998).
Estas moscas são consideradas pragas em regiões rurais e suburbanas, pois são agentes de dispersão de várias endemias. JAMES (1948) cita que, no homem, 75\% das miíases intestinais foram causadas por $F$. canicularis Linnaeus, 1761 . Os casos de miíases urogenitais e nasofaringeanas foram devido à $F$. scalaris Fabricius, 1794 (West 1951). Nos animais, míases atribuídas a estas moscas foram citadas por GreEMBERG (1971) e por Freitas et al. (1978).

Em seu trabalho, sobre a caracterização morfológica de espécies de Fannia, HewitT (1912) baseou-se nas expansões laterais (ou espinhos), as quais são mais ramificadas em $F$. scalaris do que em $F$. canicularis. Descreveu que, em $F$. canicularis, o espiráculo dorso-posterior tem uma aparência trilobulada; no entanto, exame mais detalhado revela a existência de quatro lóbulos (orifícios estigmáticos). $\mathrm{O}$ autor ainda observou que, nesta espécie, o estigma tem usualmente sete lóbulos digitiformes, sendo que este número pode variar de cinco a oito, e que, entre o segundo e o terceiro lóbulo, parece existir um órgão estigmático pequeno.

Albuguerque (1945) redescreveu $F$. trimaculata e mencionou que os estigmas, na parte lateral anterior do corpo das larvas são constituídos por sete prolongamentos 

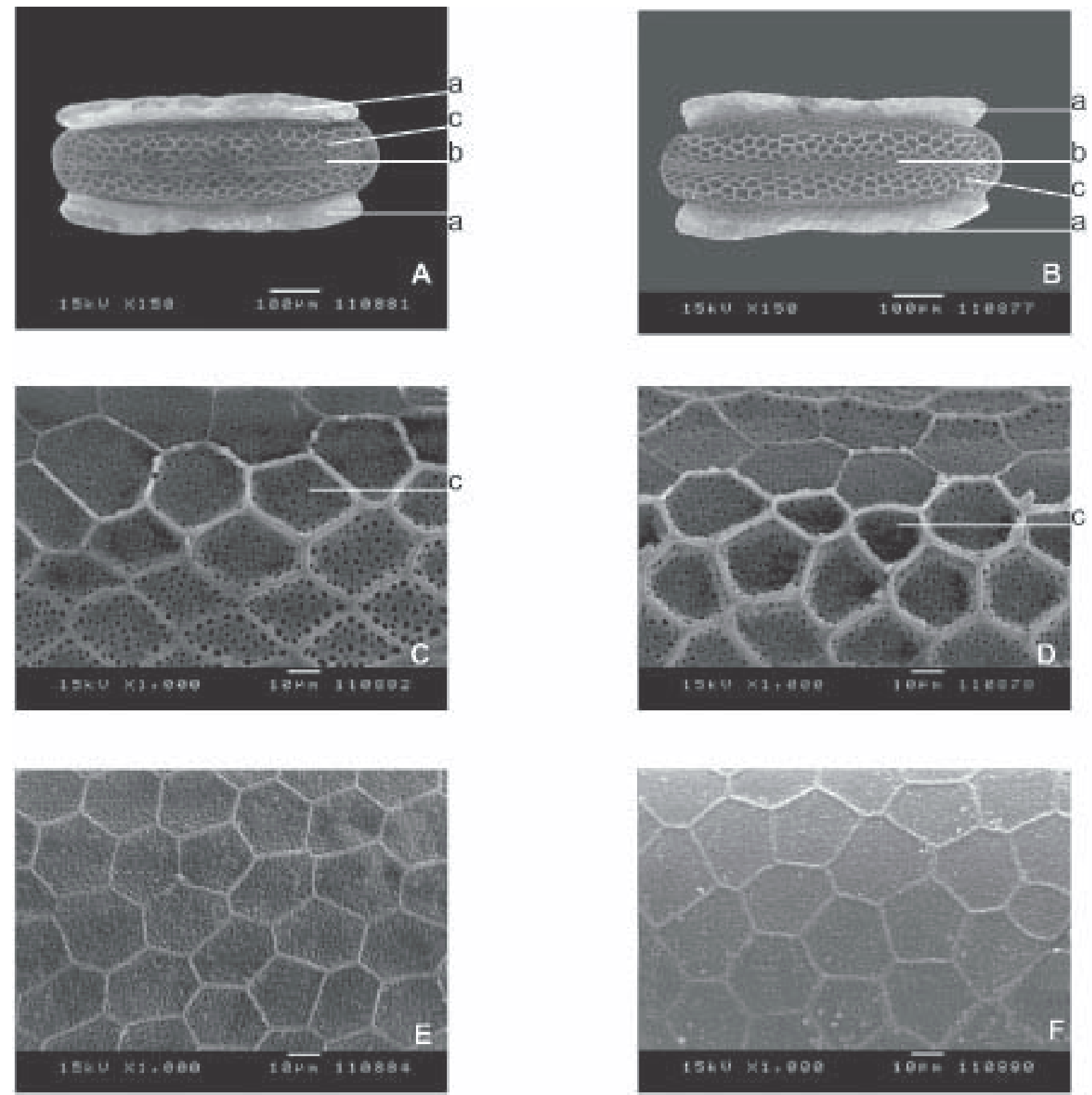

Fig. 1. Estrutura dos ovos. F. pusio (A, C e E) e F. trimaculata (B, D e F). Vista dorsal A e B; superfície dorsal C e D; superfície ventral E e F; $\mathrm{a}=$ projeções laterias; $\mathrm{b}=$ sutura mediana; $\mathrm{c}=$ "cellas".

tegumentares de aspecto anelado e, em seu interior, as traquéias apresentam-se quitinizadas. Os prolongamentos tegumentares que constituem a proteção das traquéias são unidos por uma placa tegumental. Couri (1992) descreveu o que chamou de espiráculo protorácico (estigma sensu AlbuQUerque 1945), sendo constituído em $F$. pusio por sete processos.

SeAgo (1954) mostrou que $F$. femoralis Stein, 1898 é muito parecida com $F$. pusio e CHILlcotт (1960) destacou a aparência semelhante de $F$. trimaculata com as espécies neárticas, $F$. howardi Malloch, 1913 e F. leucostica Meigen, 1826. Couri \& ARAúJo (1989) assinalaram o mesmo para F. pamplonae Couri, 1989 e F. trimaculata. AlbuQuerque et al. (1981) colocaram F. pusio e F. trimaculata no subgrupo pusio, o qual pertence ao grupo canicularis. Estes aspectos confirmam, de acordo com Chillcotт (1960), a grande semelhança morfológica que há entre as espécies de Fannia.

Albuquerque (1945) descreveu os estágios imaturos e adulto de F. trimaculata, enquanto Couri (1992) concentrouse nos estágios de ovo, larva e pupa de F. pusio.

O objetivo do presente trabalho é analisar as estruturas morfológicas encontradas nos estágios imaturos e nas imagos de $F$. pusio e F. trimaculata, com o auxílio do microscópio eletrônico de varredura. 

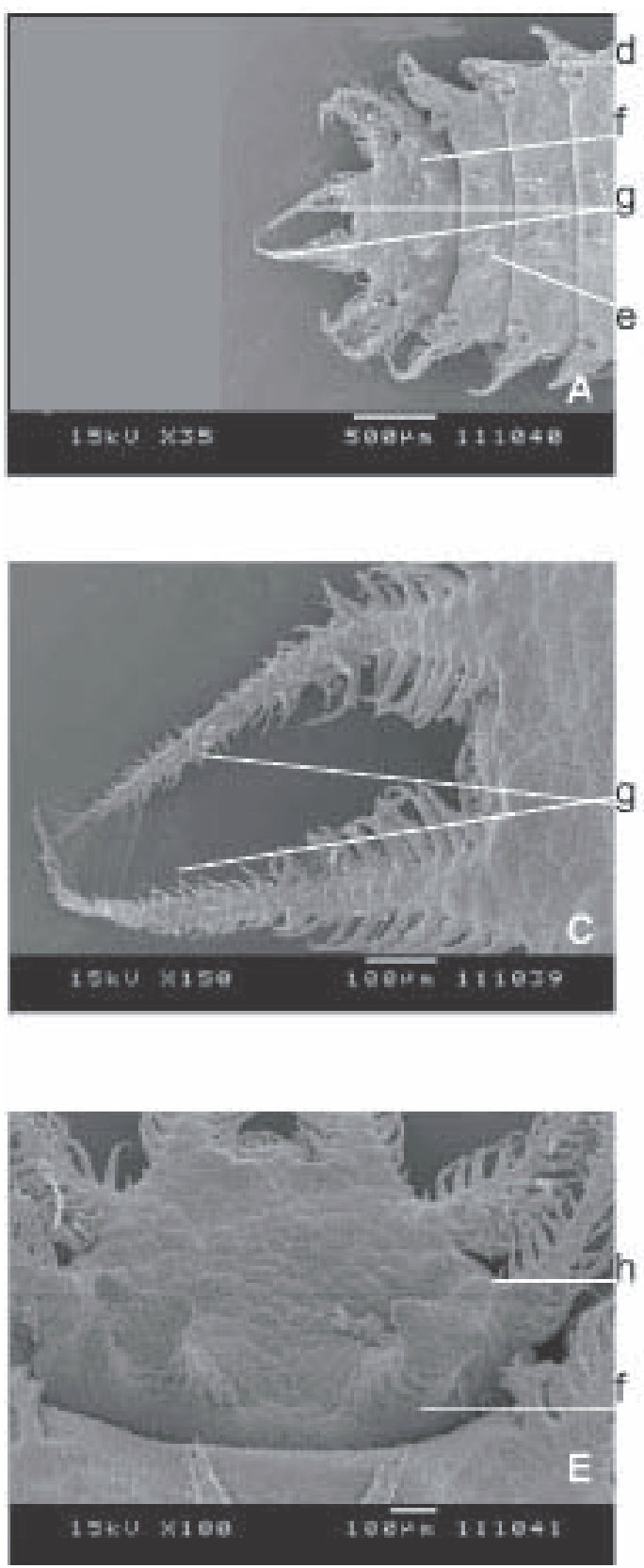
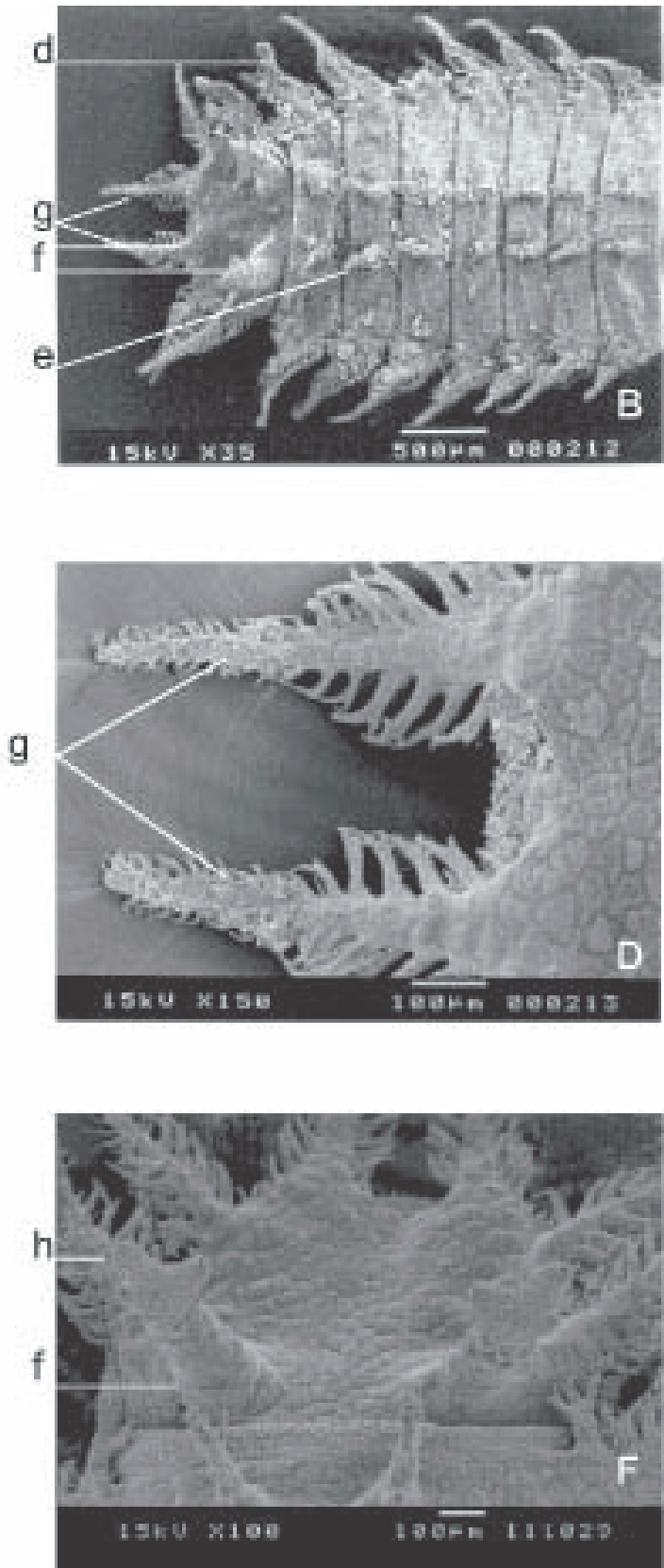

Fig. 2. Vista dorsal da larva de terceiro ínstar. F. pusio (A, C e E) e F. trimaculata (B, D e F). Segmentos posteriores A e B; segmento anal C e D; espiráculo dorso-posteriores ampliados com as aberturas $\mathrm{E}$ e $\mathrm{F}$; $\mathrm{d}=$ expansões laterais; $\mathrm{e}=$ =pedúnculos dorsais; $\mathrm{f}=$ =espiráculo dorso-posterior; $\mathrm{g}=$ =expansões anais; $\mathrm{h}=$ aberturas.

\section{MATERIAL E MÉTODOS}

Exemplares de Fannia pusio e F. trimaculata foram capturados em granjas de galinhas poedeiras com uma rede entomológica, a qual era passada sobre as fezes depositadas no chão. A captura ocorreu na zona rural do município de Bady Bassit, São Paulo e na granja da Faculdade de Ciências Agrárias e Veterinárias - Universidade Estadual Paulista Júlio de Mesquita Filho, Câmpus de Jaboticabal, São Paulo. A identificação das espécies deu-se de acordo com SEAGO (1945).
Os indivíduos da linhagem de Jaboticabal foram identificados como Fannia pusio e os provenientes de Bady Bassitt, como F. trimaculata.

No laboratório, as moscas foram mantidas em caixas de isopor (20 litros) modificadas (Alves 2001). Para manutenção dos espécimes foi usada uma mistura de leite em pó e açúcar (1:1). A água foi colocada em recipiente separado. Os ovos foram colhidos em placa de Petri, com meio de cultura à base de farelo de trigo. Posteriormente, foram transferidos para recipientes de plástico transparente para o desenvolvimento 

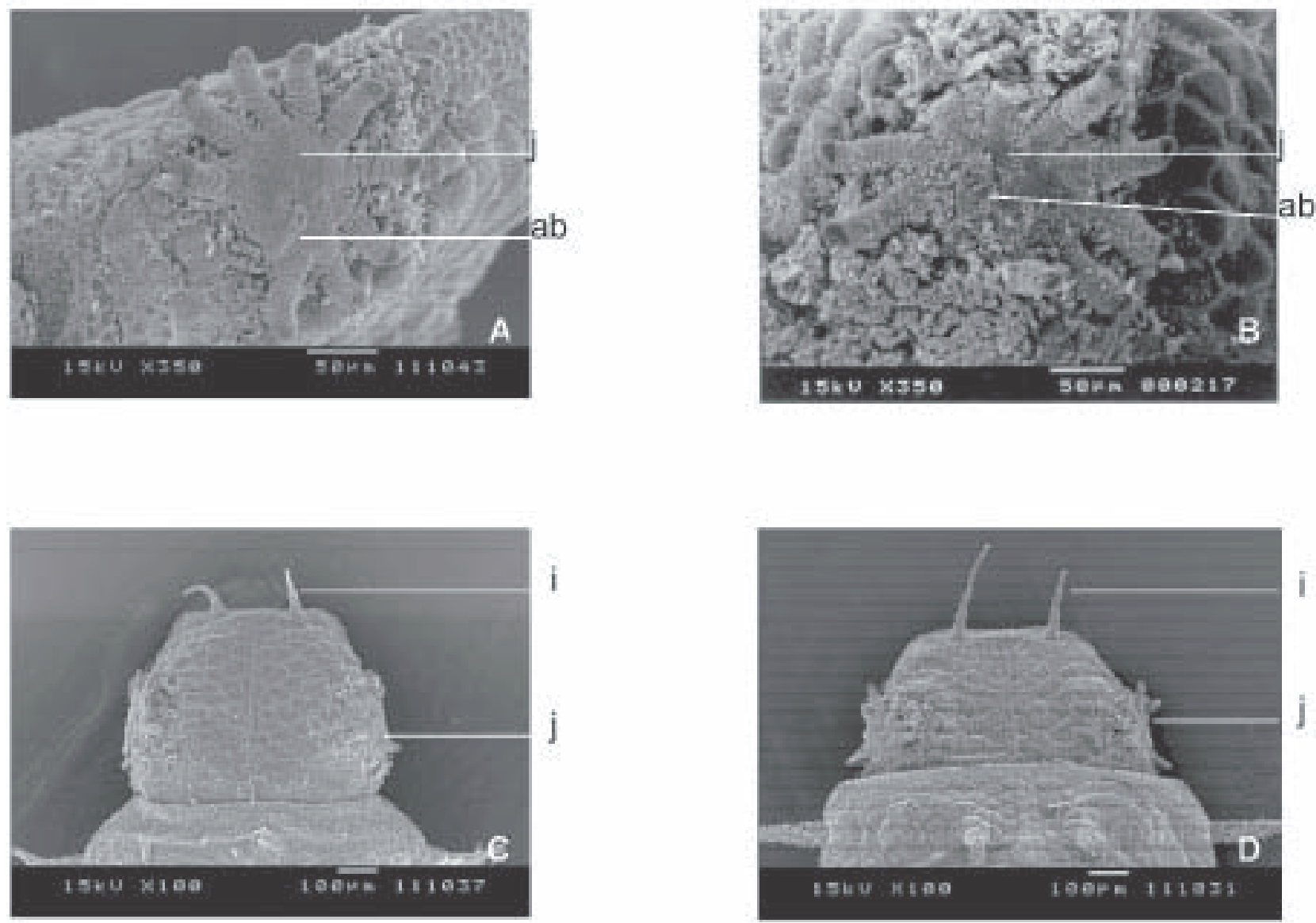

Fig. 3. Vista dorsal da larva de terceiro ínstar. F. pusio (A e C) e F. trimaculata (B e D). Segmento dorsal A e B; segmento lateral C e D; i="antenas"; $\mathrm{j}=$ estigmas; $a b=$ saliências.

em larvas e obtenção dos imagos.

Para análise em microscópio eletrônico de varredura (MEV), ovos, larvas, pupas, pernas e cabeças de no mínimo 10 exemplares das duas espécies foram limpos com um pincel fino. As cabeças e as pernas foram dissecadas com o auxílio de um estereomicroscópio Wild M-5. As estruturas foram montadas e fixadas utilizando-se uma fita adesiva de dupla face, sobre porta-espécimes metálicos de aproximadamente 10 $\mathrm{mm}$ de diâmetro por $10 \mathrm{~mm}$ de altura, com as estruturas morfológicas de interesse voltadas para cima. A preparação das larvas para análise ao MEV foi efetuada conforme SANTOS $\& \operatorname{MaIA}(1997)$.

O material testemunho do estudo é mantido no Laboratório de Genética Ecológica do Departamento de Biologia Aplicada a Agropecuária da Faculdade de Ciências Agrárias e Veterinárias da Universidade Estadual Paulista Júlio de Mesquita Filho, Câmpus de Jaboticabal, São Paulo.

\section{RESULTADOS}

Ovo. A Fig. 1 mostra estruturas dos ovos de F. pusio (A, C e E) e de F. trimaculata (B, D e F), que são de coloração clara e medem 620 ìm de comprimento em F. pusio (1A) e $650 \mu \mathrm{m}$ em F. trimaculata (1B). Nos ovos de ambas as espécies são observadas duas projeções lateralmente dispostas e não ornamentadas (a). Em ambos os casos, na superfície dorsal do ovo, observa-se uma sutura longitudinal (b). Tal estrutura não ocorre na superfície ventral.

O tegumento que envolve o ovo das duas espécies apresenta retículos (c) com padrões tendendo ao hexágono (celas). As celas da superfície dorsal têm orifícios (Figs. 1C e 1D) em números variados, sendo que em $F$. pusio eles ocorrem em maior número e são maiores que os observados em $F$. trimaculata. As Figs. 1E e 1F mostram a parte ventral dos ovos das duas espécies de moscas. Observa-se, no ovo de $F$. pusio, que o tegumento dentro das celas exibe a superfície mais rugosa que em $F$. trimaculata. Nesta face não ocorrem os orifícios, observados na face dorsal.

Larva. As larvas analisadas eram de terceiro ínstar e apresentaram coloração marrom. A Fig. 2 ilustra a face dorsal das larvas que apresentam, em cada segmento, com exceção do primeiro e do último, um par de pedúnculos dorsais (e).

As larvas das duas espécies apresentam, de cada lado do 

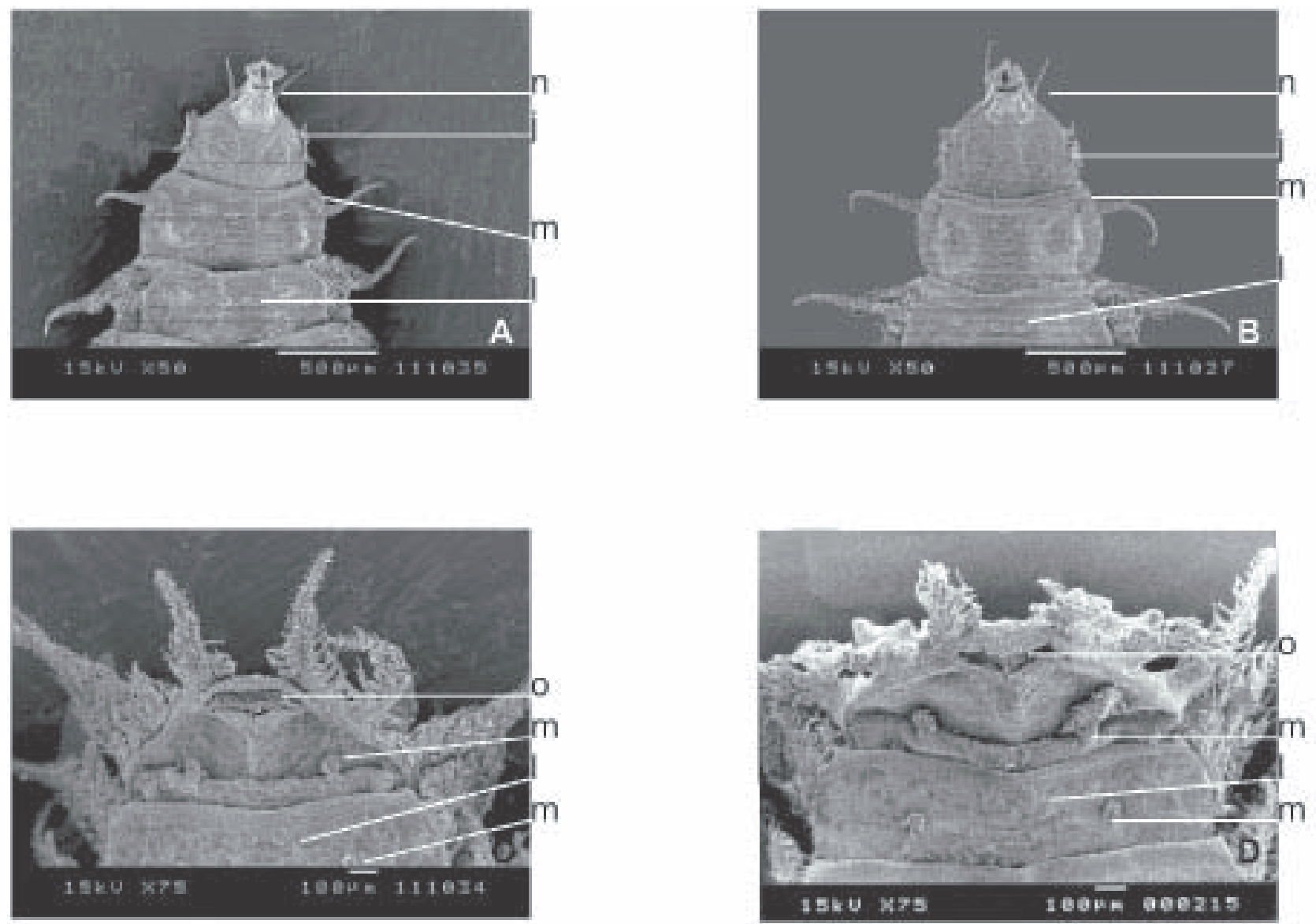

Fig. 4. Vista ventral da larva de terceiro ínstar. F. pusio (A e C) e F. trimaculata (B e D). Segmento anterior A e B; segmento posterior C e D; $\mathrm{n}=$ "aparelho bucal"; $1=$ pedúnculos ventro-medianos; $m=$ pedúnculos ventro-laterais; $\mathrm{o}=$ ânus; $j=$ estigmas.

corpo, uma expansão ou espinho (d), com exceção do último segmento, que exibe um par de expansões laterais, além de duas expansões terminais (g), sendo uma de cada lado do ânus. Estes segmentos anais apresentam diferenças estruturais, sendo que em F. trimaculata (2D) metade dos mesmos apresenta ramificações laterais longas e espessas, enquanto que a outra metade, ramificações bem mais curtas e finas. Neste sentido, ocorre uma semelhança com F. pusio; entretanto as ramificações mais longas e mais espessas em $F$. pusio não chegam a $40 \%$ do total da expansão anal ou espinho. Estas estruturas (espinhos) são mais longas em F.pusio (2C) que em $F$. trimaculata.

As duas espécies (Figs. 2E e 2F) apresentam na parte anterior do segmento anal duas expansões denominadas de espiráculos dorso-posterior (f) que, na sua parte distal, apresentam quatro ramificações ou aberturas (h).

As Figs. 3A e 3B apresentam o estigma ou espiráculo protorácico das duas espécies. Esta estrutura possui um corpo central esférico de onde saem prolongamentos tegumentares de aspecto anelado (Albuquerque 1945), referidos como aberturas espiraculares (COURI 1992). Em ambas as espécies, há nove ramificações ou prolongamentos que partem radialmente desta estrutura central, e uma saliência (ab) no corpo central, que apresenta uma abertura em sua parte distal. Esta saliência tem o formato cônico, dando o aspecto de um pequeno "vulcão".

O pseudocéfalo, na região anterior e dorsal das larvas (Fig. 3 ), é mais longo e mais estreito em $F$. pusio (3C) que em $F$. trimaculata (3D) e "antenas" (i) mais curtas que as observadas para F. trimaculata.

$\mathrm{Na}$ parte anterior e ventral das larvas (Fig. 4), há similaridades entre os aparelhos bucais (n); entretanto, parece não haver diferenças estruturais nos orifícios da parte apical entre as linhagens. Na região central de cada segmento, com exceção do primeiro e do último, há um par de pedúnculos ventro-medianos (1) e um par de pedúnculos ventro-laterais (m) que se distribuem por todos os segmentos, com exceção do primeiro. No último segmento, os pedúnculos ventrolaterais são mais longos que os anteriores.

Pupa. A Fig. 5 ilustra a parte dorsal das pupas de F. pusio (A, C e E) e F. trimaculata (B, D e F), que apresentam coloração marrom. As Figs. 5C e 5D são relativas às projeções ampliadas de pares de pedúnculos dorsais (e) de ambas as espécies. Não 

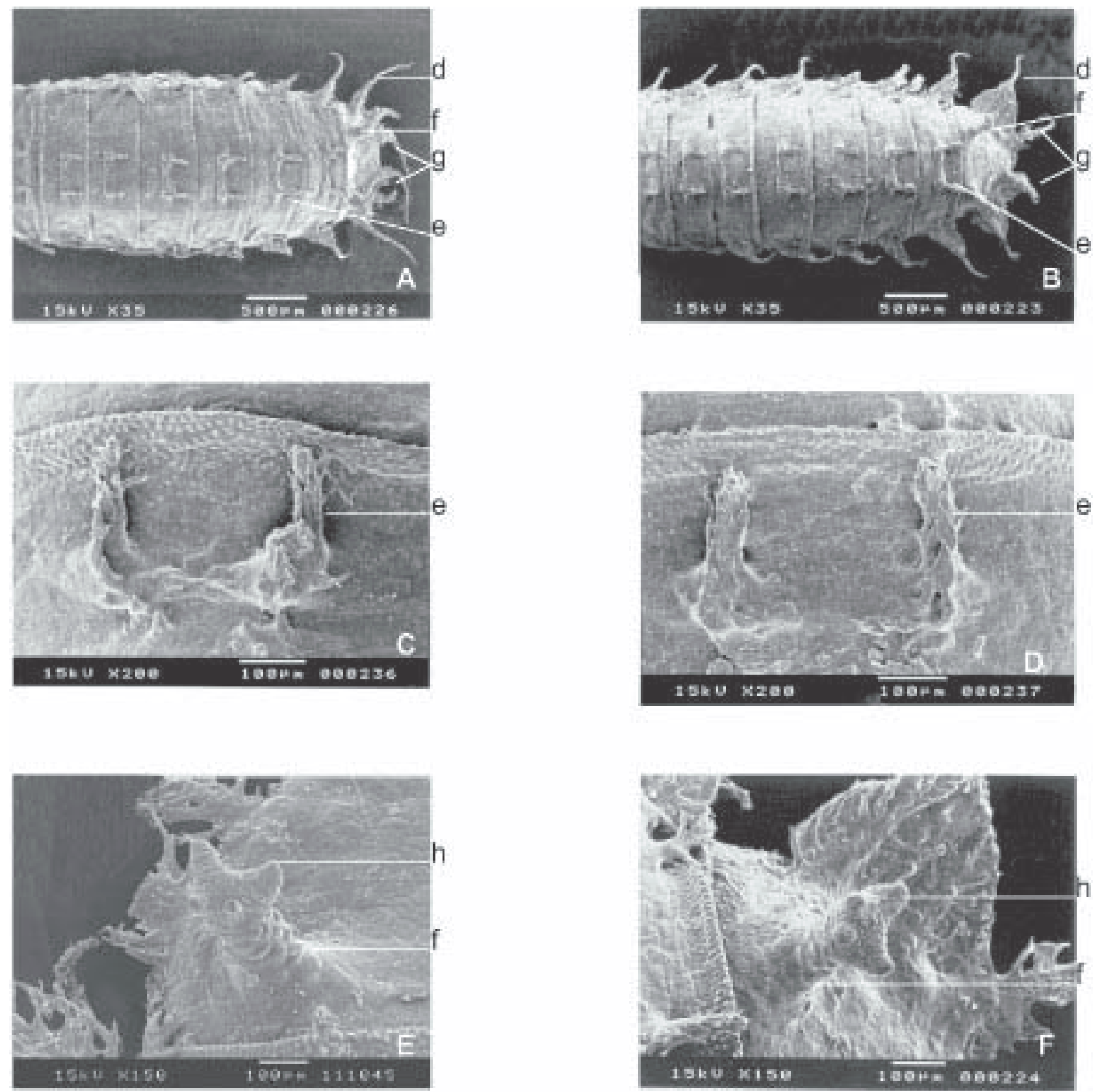

Fig. 5. Vista dorsal de pupas. F. pusio (A, C e E) e F. trimaculata (B, D e F). Vista dorsal A e B; segmento dorsal C e D; espiráculo dorso-posteriores ampliados com as aberturas $\mathrm{E}$ e F; e=pedúnculos dorsais; $\mathrm{d}=$ =xpansões laterais; $\mathrm{g}=$ expansões anais; $\mathrm{f}=$ pedúnculos dorso-posteriores; $\mathrm{h}=\mathrm{aberturas}$.

há diferenças entre eles. As projeções ampliadas (Figs. 5E e 5F) dos espiráculos dorso posteriores (f) das duas espécies mostram claramente, na sua parte apical, quatro aberturas (h).

No nono segmento (a partir do pseudocéfalo), na parte ventral das pupas (Fig. 6), há um par de pedúnculos ventromedianos (l) e um par de pedúnculos ventro-laterais (m). Entre estes existe uma fileira de "papilas" (p) que mostraram configurações diferentes nas duas espécies. As projeções ampliadas dos pedúnculos ventro-medianos (1) do nono segmento apresentam, em sua periferia, 14 expansões ou papilas em F. pusio e 13 em F. trimaculata (Figs. 6E e 6F).

Adulto. A cabeça dos machos de ambas as espécies (Fig. 7) apresenta, estruturas similares em relação aos aspectos morfológicos. Entretanto, nota-se que a distância a partir da base inferior da projeção do triângulo ocelar (v) até o primeiro par de cerdas da fileira vertical interna das cerdas frontais (z) é maior em F. pusio $(160 \mu \mathrm{m})$ do que em F. trimaculata $(110 \mu \mathrm{m})$.

As projeções ampliadas dos palpos maxilares (u) e das facetas (k) dos machos, mostraram, que em F. trimaculata 

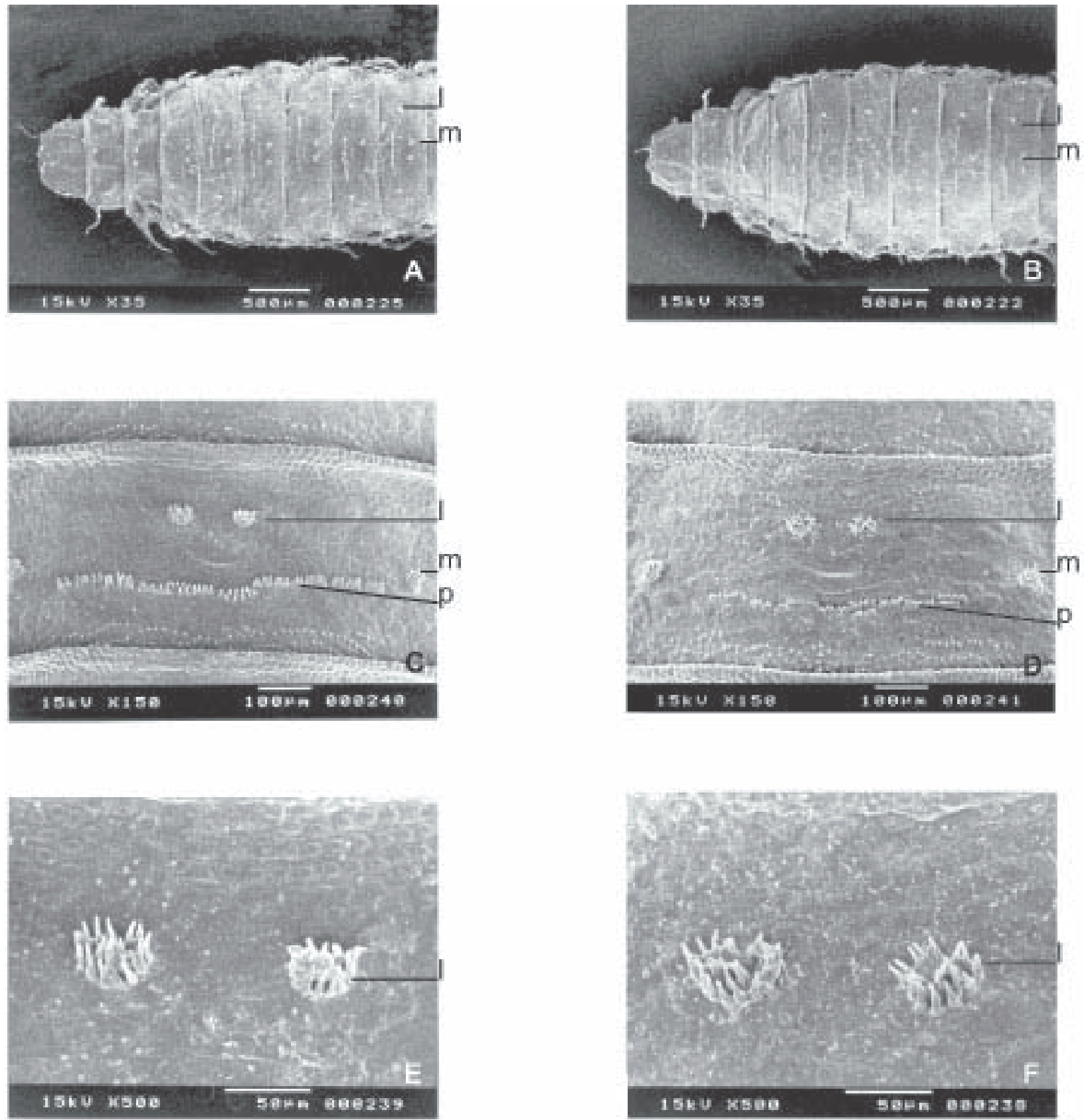

Fig. 6. Vista ventral de pupas. F. pusio (A, C e E) e F. trimaculata (B, D e F). Vista ventral A e B; segmento ventral C e D; pedúnculos ventromedianos ampliados E e F; $1=$ pedúnculos ventro-medianos; $m=$ pedúnculos ventro-laterais; $p=$ "papilas".

(Fig. 8B), são mais longos e com maior número de cerdas na parte distal que em $F$. pusio (Fig. 8A). Os machos de $F$. trimaculata (Fig. 8D) têm uma fileira de cinco cerdas menores ao lado de uma fileira de cerdas maiores, localizadas mais externamente na faceta $(\mathrm{k})$. Esta fileira de cerdas menores não ocorre em machos de F. pusio (Fig. 8C).

Nas fêmeas de ambas as espécies, abaixo do triângulo ocelar (v) há um outro triângulo (ac) entre as cerdas frontais (z), o qual é mais longo em $F$. pusio (Fig. 9A) do que em $F$. trimaculata (Fig. 9B). A vista frontal é maior e mais pilosa em
F. trimaculata $(230 \mu \mathrm{m})$ do que em $F$. pusio $(180 \mu \mathrm{m})$.

Há uma saliência de "pêlos" na parte central do triângulo ocelar (v) em F. pusio (Fig. 9C), sendo esta região ligeiramente pilosa em F. trimaculata (Fig. 9D). Os palpos maxilares (u) de fêmeas (Figs. 10A e 10B) são ligeiramente maiores em $F$. trimaculata $(460 \mu \mathrm{m})$ do que em $F$. pusio, $(430 \mu \mathrm{m})$. As fêmeas de ambas as espécies possuem uma fileira de cerdas menores na faceta $(\mathrm{k})$ que a fileira de cerdas mais externas (Figs. 10C e 10D).

O fêmur posterior dos machos de F. trimaculata (Fig. 11B) 

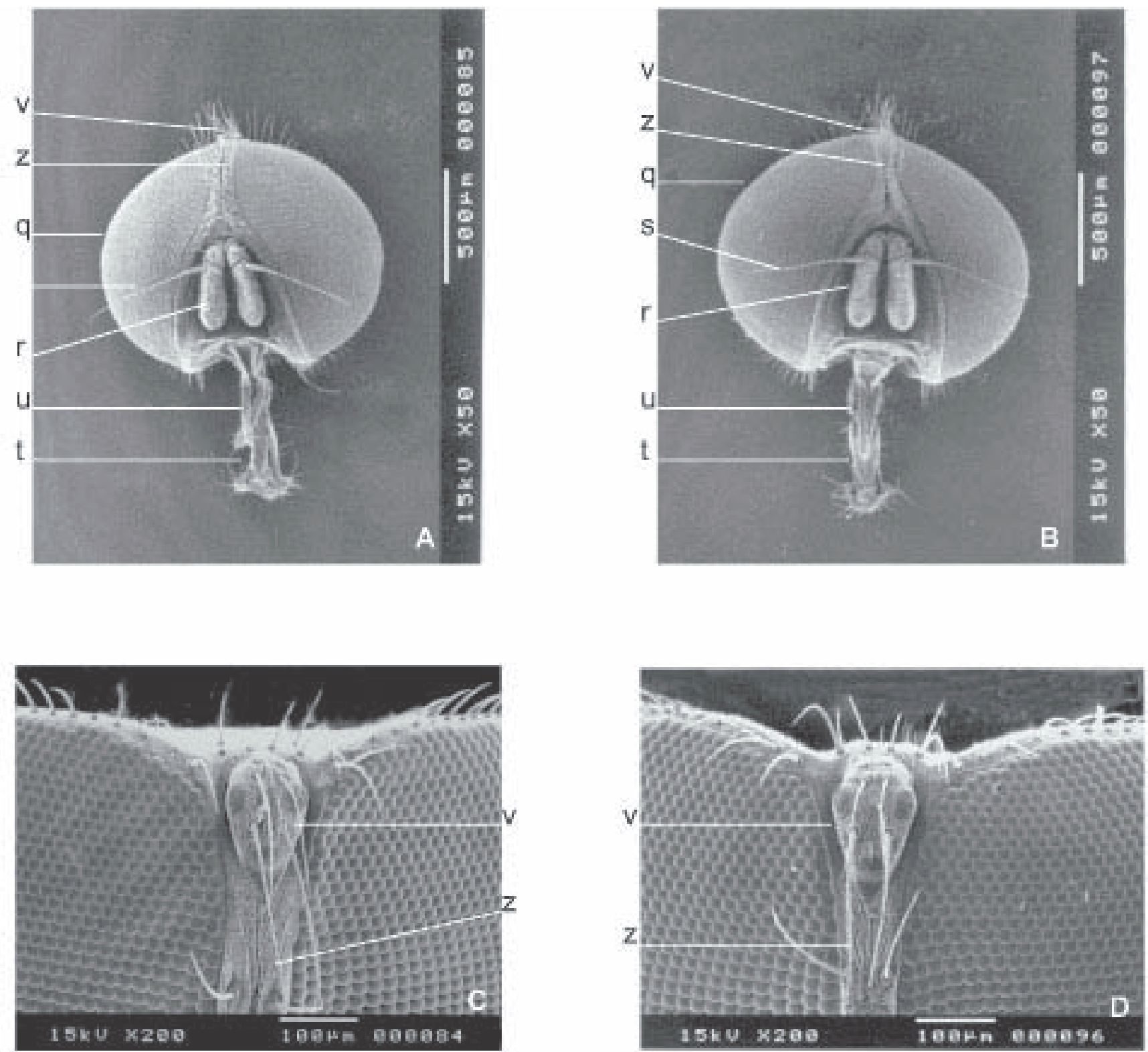

Fig. 7. Vista da cabeça de machos. F. pusio (A e C) e F. trimaculata (B e D). Vista frontal A e B; olhos compostos ampliados C e D; q=olhos compostos; $r=$ antenas; $s=$ aristas; $\mathrm{t}=$ probócida; $\mathrm{u}=$ =palpos maxilares; $\mathrm{v}=$ triângulo ocelar; $\mathrm{z}=$ =fileira vertical interna de cerdas frontais.

apresenta uma fileira com oito cerdas que, segundo SEAGO (1954), pode variar de sete a oito cerdas, e que não ocorre, de acordo com o autor, em F. pusio (Fig. 11A). Esta característica é usualmente utilizada para separar as duas espécies.

\section{DISCUSSÃO}

Os dados sobre a estrutura anatômica dos ovos não apresentaram características básicas que, por si só, possibilitem a identificação das duas espécies. AlbuQuerQue (1945), ao descrever a morfologia dos ovos de F. trimaculata, não assinalou a presença das "cellas" e a estrutura que CourI
(1992) descreveu como hexagonal, deve ser a mesma observada no presente trabalho. A larva, ao eclodir, sai do ovo através da sutura longitudinal.

As espécies do gênero Fannia apresentam caracteristicamente larvas achatadas dorso-ventralmente, as quais mostram expansões laterais (espinhos) em todos os segmentos, exceto no pseudocéfalo. Foi verificado que as larvas de terceiro ínstar de $F$. pusio e F.trimaculata apresentam 12 segmentos. HewitT (1912) também cita 12 segmentos em $F$. canicularis e F. scalaris; enquanto que QueIroz \& CARVALHO (1987) citam 13 segmentos em F. canicularis e $12 \mathrm{em}$ F. scalaris. Albuquerque (1945) descreveu 12 segmentos em $F$. 

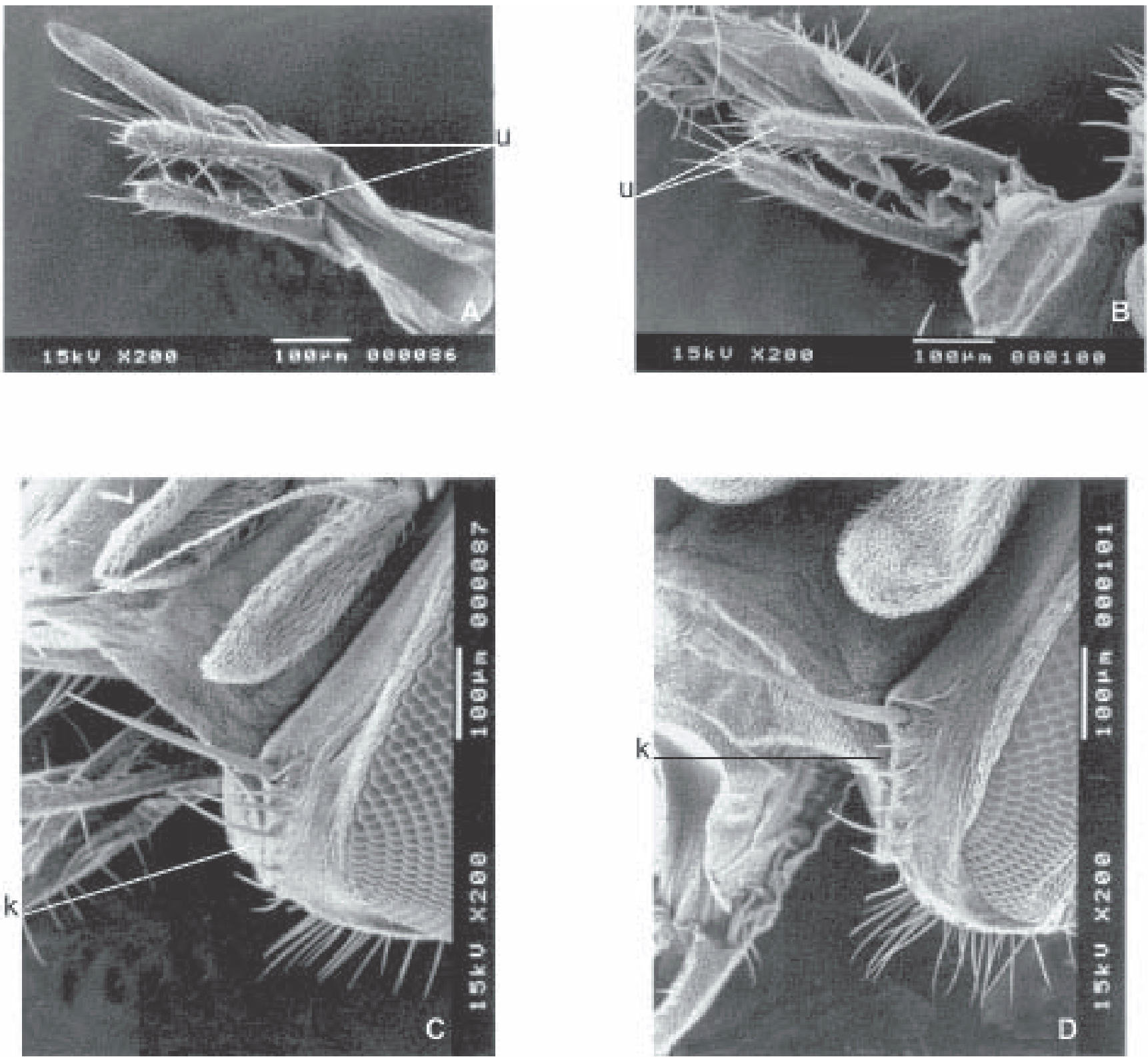

Fig. 8. Vista da cabeça de machos. F. pusio (A e C) e F. trimaculata (B e D). Palpos maxilares ampliados A e B; facetas ampliadas C e D; u=palpos maxilares; $\mathrm{k}=$ faceta.

trimaculata e CouRI (1992), apesar de não ter se referido especificamente ao número, seus esquemas confirmam 12 segmentos para larvas de F. pusio.

As larvas apresentam, com exceção do primeiro e do último segmento, um par de expansões na face dorsal, as quais foram denominadas por AlBuQUERQue (1945) de pedúnculos dorsais e por Couri (1992) de processos dorso-medianos de segmentos. Estas estruturas são semelhantes nas duas espécies analisadas. Diferenças foram assinaladas para as expansões anais ou espinhos, os quais são mais longos em F.pusio. Nas expansões laterais, não foram detectadas diferenças entre as duas espécies.
No último segmento (anal), há um par de espiráculos dorsoposteriores, os quais são mais longos que os pedúnculos dorso-medianos. Há controvérsias em relação ao número de aberturas da parte distal desta estrutura. AlBuQuerque (1945) e Couri (1992) citam três aberturas. Nossas observações em $F$. pusio e em F. trimaculata, mais as de Hewitt (1912), em $F$. canicularis e F. scalaris, apontam quatro aberturas. A estrutura, citada por QueIroz \& CARvalho (1987) como brânquias, provavelmente corresponde às aberturas, com o número de quatro em $F$. canicularis e de três em $F$. scalaris. Como há muitas controvérsias a respeito da fixação de um número básico, torna-se difícil caracterizar grupos ou espécies 

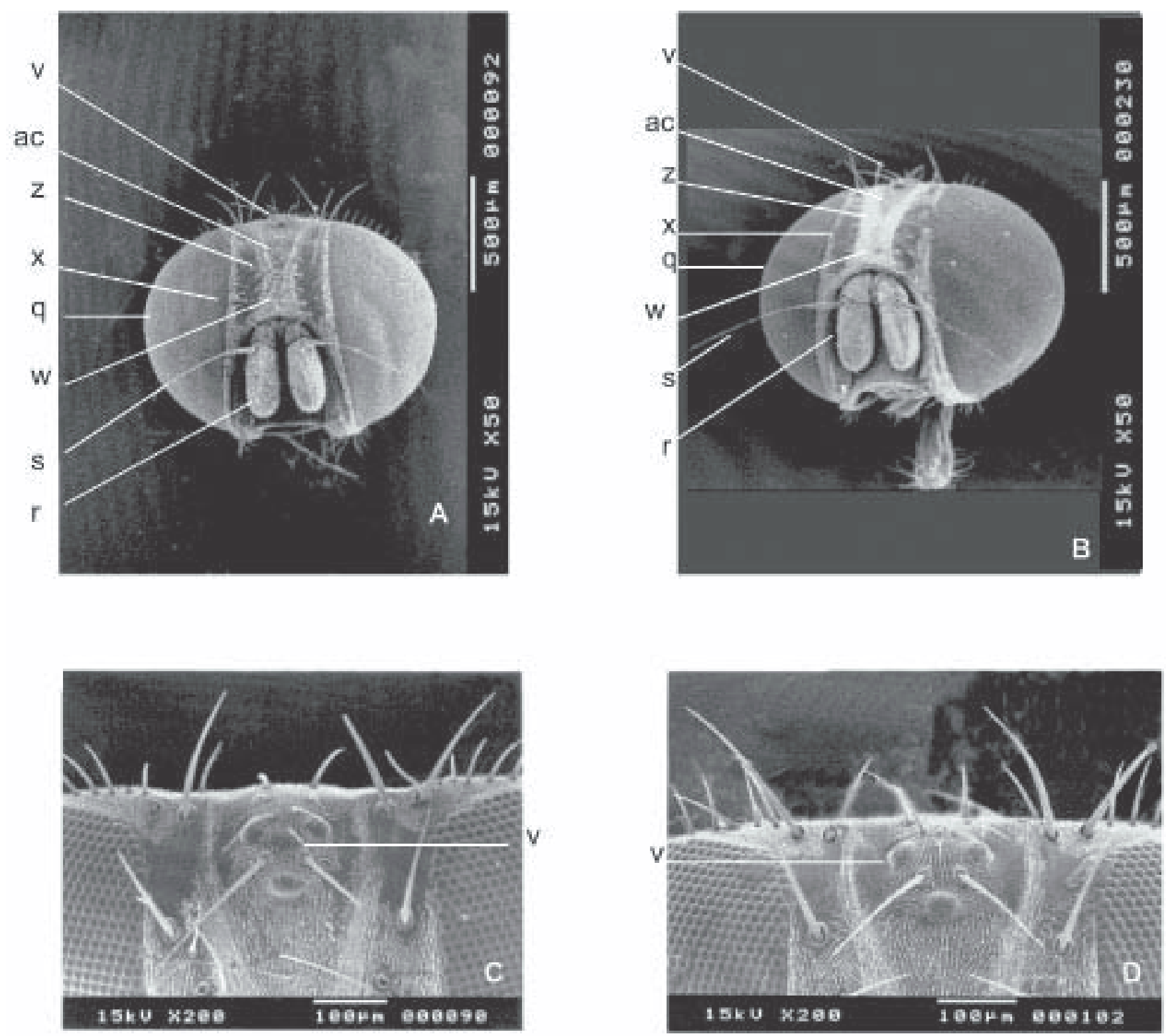

Fig. 9. Vista da cabeça de fêmeas. F. pusio (A e C) e F. trimaculata (B e D). Vista frontal A e B; olhos compostos ampliados C e D; ac=triângulo; $\mathrm{q}=\mathrm{olhos}$ compostos; $\mathrm{r}=$ antenas; $\mathrm{s}=$ aristas; $\mathrm{v}=$ triângulo ocelar; $\mathrm{w}=$ fronte; $\mathrm{x}=$ cerdas parafrontais; $\mathrm{z}=$ cerdas frontais.

em relação a este aspecto.

Quanto ao estigma ou espiráculo protorácico, Albuquerque (1945) cita sete prolongamentos tegumentares para F. trimaculata e Couri (1992) descreveu também sete para F. pusio. Hеwitт (1912) observou sete prolongamentos com variação de cinco a oito em $F$. canicularis e $F$. scalaris. As observações com microscopia eletrônica de varredura indicam para F. pusio e F. trimaculata, nove prolongamentos tegumentares, sendo que, em $F$. trimaculata, há dois prolongamentos tegumentares que são bem menores que os outros. Nesta estrutura do pseudocéfalo, há uma região que chamamos de corpo central de onde saem os prolongamentos tegumentares. Neste corpo central há uma estrutura saliente que, devido à sua forma cônica, dá o aspecto de "vulcão". Hewitt (1912) a denominou de órgão estigmático pequeno.

Os espiráculos dorso-posteriores aparecem nas pupas mais claramente que nas larvas de ambas as espécies de Fannia, apresentando, na sua parte apical, quatro aberturas. Na parte ventral dos segmentos das pupas, as fileiras formadas pelas papilas apresentaram configurações diferentes nas duas espécies. Diferenças morfológicas assinaladas entre as duas espécies estão relacionadas também com o número de papilas dos pedúnculos ventro-medianos.

Na cabeça de machos das duas espécies, foram detectadas diferenças relacionadas com a distância existente entre a base do triângulo ocelar (vértice) com o primeiro par de cerdas da 

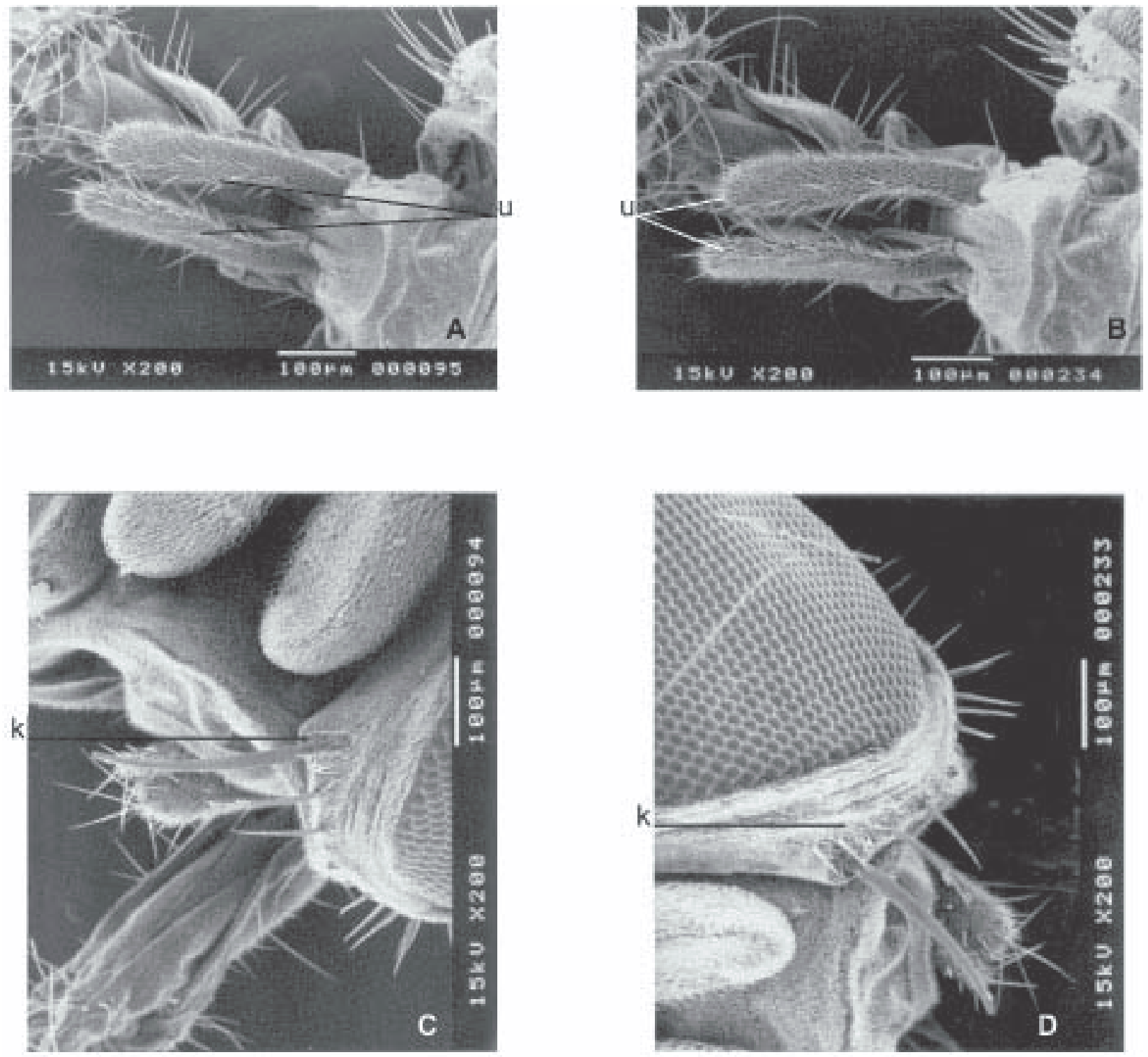

Fig. 10. Vista da cabeça de fêmeas. F. pusio (A e C) e F. trimaculata (B e D). Palpos maxilares ampliados A e B; facetas ampliadas C e D; u=palpos maxilares; $\mathrm{k}=$ faceta com a fileira interna de cerdas.
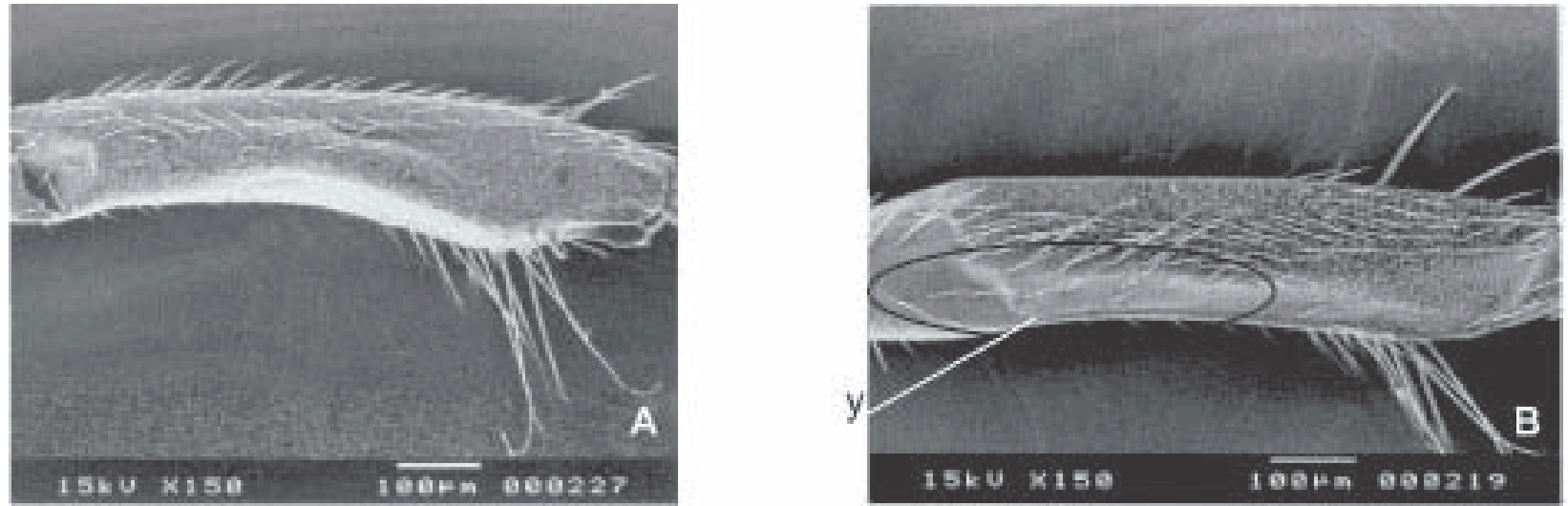

Fig. 11. Vista do fêmur posterior. F. pusio (A) e F. trimaculata (B). Vista lateral A e B; y=fileira com oito cerdas. 
fileira vertical interna das cerdas frontais (z); outra observação diz respeito aos palpos maxilares, nos machos e nas fêmeas, os quais são mais longos em F. trimaculata que em F. pusio. A existência de uma fileira constituída por cinco cerdas ao lado das cerdas maiores, localizadas mais externamente, em relação à área da faceta de $F$. trimaculata, pode ser uma boa característica para identificação destas espécies, com base na morfologia de machos.

Chillcott (1960) também notou o triângulo (ac), formado por pequenos "pêlos" diferenciados, abaixo do triângulo ocelar. Nas espécies analisadas, este triângulo, como foi visto, parece ser maior em fêmeas de $F$. pusio. O número de pêlos na vita frontal (ac), é maior em fêmeas de F. trimaculata que em $F$. pusio.

\section{REFERÊNCIAS}

Aagesen, T. L. 1988. Artrópodes associados a excrementos em aviários. Dissertação de Mestrado. Piracicaba, Escola Superior de Agricultura "Luiz de Queiroz", Universidade de São Paulo, 38 p.

Albuquerque, D. O. DE. 1945. Sobre Fannia trimaculata (Stein, 1897) Malloch, 1913. (Diptera, Muscidae). Boletim do Museu Nacional 34: $1-16$.

Albuquerque, D. O. De; D. Pamplona \& C. J. B. de Carvalho. 1981. Contribuição ao conhecimento dos Fannia R. D., 1830 da região neotropical (Diptera, Fanniidae). Arquivos do Museu Nacional 56: $9-34$

Alves, S. M. 2001. Padrões esterásicos e populacionais em Muscina stabulans (Fallén) (Diptera: Muscidae) em relação a dois tipos de inseticidas. Tese de Doutorado. Jaboticabal, UNESP, 143 p.

Axtell, R. C. 1986. Fly control in confined livestock and poultry production. Ciba-Geigy Corporation, Tech. Monograph, Greensboro, N. C., 59 p.

BéLo, M. 1991. Freqüência estacional de moscas emergidas em fezes de galinhas poedeiras. Boletim de Ciência Agronômica 6(1): 2124.

Bélo, M.; S. M. Alves \& D. J. Pires. 1998. Flutuações e diversidade de espécies de dípteros em granjas de galinhas poedeiras. Bioikos 12(2): 36-44.

Bruno, T. V.; J. H. Guimarães; A. M. M. dos Santos \& E. C. Tucci. 1993. Moscas sinantrópicas (Dipera) e seus predadores que se criam em esterco de aves poedeiras confinadas, no Estado de São Paulo, Brasil. Revista Brasileira de Entomologia 37(3): 577-590.

Carvalho, C. J. B. De; A. C. Pont; M. S. Couri \& D. Pamplona. 2003. A catalogue of the Fanniidae (Diptera) of the Neotropical Region. Zootaxa 219: 1-32.

Снillcotт, J. G. 1960. A revision of the Nearctic species of Fanniidae
(Diptera: Muscidae). The Canadian Entomologist 92: 5-295.

Chillcott, J. G. 1961. The new species of Fannia R.-D. (Diptera: Muscidae) from the Palaeartic and Oriental regions. The Canadian Entomologist 93(2): 81-92.

Couri, M. S. 1992. Imature stages of Fannia pusio (Wiedemann, 1830) (Diptera, Fanniidae). Revista Brasileira de Biologia 52(1): 8391.

Couri, M. S. \& P. F. de Araúso. 1989. Uma nova espécie de Fannia Robineau-Desvoidy, 1830 do Brasil (Diptera: Fanniidae). Revista Brasileira de Zoologia 6(4): 617-620.

Freitas, M. G.; H. M. A. Costa; J. O. Costa \& P. Iide. 1978. Entomologia e acarologia médica e veterinária. $4^{\mathrm{a}}$. ed. Belo Horizonte, Rabelo e Brasil, 253 p.

Guimarães, J. H. 1984. Moscas: biologia, ecologia e controle. Agroquímica Ciba-Geigy 21: 20-26.

Guimarães, J. E.; N. Papavero \& A. P. Prado. 1983. As mí́ases na região neotropical (identificação, biologia, bibliografia). Revista Brasileira de Zoologia 1(4): 239-416.

Greenberg, B. 1971. Flies and disease. New Jersey, Princeton University Press, $856 \mathrm{p}$.

Hewitt, C. G. 1912. Fannia (Homalomyia) canicularis Linn. and $F$. scalaris Fab. Parasitology 5(3): 161-174.

JAmES, M. T. 1948. The larvae of flies that cause myisis in man. United States Department Agriculture Miscellaneous Publications 631: $175 \mathrm{p}$

Lomônaco, C. \& A. P. Do Prado. 1994. Estrutura comunitária e dinâmica populacional da fauna de dípteros e seus inimigos naturais em granjas avícolas. Anais da Sociedade Entomológica do Brasil 23(1): 71-80.

Prado, A. P. Do. \& O. B. Ribeiro. 1989. Levantamento e distribuição sazonal da entomofauna que se desenvolve em esterco de aves poedeiras e seus inimigos naturais em uma granja de Monte Mor SP: I. Ocorrência de Fannia trimaculata (Stein, 1897) (Diptera: Fanniidae). Arquivos do Instituto Biológico de São Paulo 56: $78 \mathrm{p}$.

Queiroz, S. M. P. De \& C. J. De Carvalho. 1987. Chave pictórica e descrições de larvas de $3^{\circ}$ ínstar de Diptera (Calliphoridae, Muscidae e Fanniidae) em vazadouros de resíduos sólidos domésticos em Curitiba, Paraná. Anais da Sociedade Entomológica do Brasil 16(2): 265-288.

Ribeiro, O. B. \& A. P. do Prado. 1989. Levantamento e distribuição sazonal da entomofauna que se desenvolve em esterco de aves poedeiras e seus inimigos naturais, em granja de Monte Mor - SP: II. Flutuação populacional de Fannia trimaculata (Stein, 1897) (Diptera: Fanniidae). Arquivos do Instituto Biológico de São Paulo 56: 1-79.

Santos, J. M. \& A. S. MaiA. 1997. A SEM improved technique for studying host-pathogen interactions of sedentary nematodes and for documentation of perineal patterns of Meloidogyne spp. Acta Microscópica 6: $562-563$.

Seago, J. M. 1954. The Pusio group of the genus Fannia RobineauDesvoidy, with descriptions of new species (Diptera, Muscidae). American Museum Novitates 1699: 1-13.

West, L. S. 1951. The housefly. New York, Comstock Publishing Company, $584 \mathrm{p}$.

Recebido em 20.V.2003; aceito em 15.III.2004 